\title{
Coordinated within-Trial Dynamics of Low-Frequency Neural Rhythms Controls Evidence Accumulation
}

\author{
Markus Werkle-Bergner, ${ }^{1}$ Thomas H. Grandy, ${ }^{1}$ Christian Chicherio, ${ }^{1,2}$ Florian Schmiedek, ${ }^{1,3}$ Martin Lövdén, ${ }^{1,4}$ \\ and Ulman Lindenberger ${ }^{1}$ \\ ${ }^{1}$ Max Planck Institute for Human Development, D-14195 Berlin, Germany, ${ }^{2}$ Neuropsychology Unit, Neurology Clinic, Geneva University Hospitals, CH- \\ 1211 Geneva 14, Switzerland, ${ }^{3}$ German Institute for International Educational Research, D-60486 Frankfurt am Main, Germany, and ${ }^{4}$ Aging Research \\ Center, Karolinska Institutet \& Stockholm University, SE-113 30 Stockholm, Sweden
}

Higher cognitive functions, such as human perceptual decision making, require information processing and transmission across widespread cortical networks. Temporally synchronized neural firing patterns are advantageous for efficiently representing and transmitting information within and between assemblies. Computational, empirical, and conceptual considerations all lead to the expectation that the informational redundancy of neural firing rates is positively related to their synchronization. Recent theorizing and initial evidence also suggest that the coding of stimulus characteristics and their integration with behavioral goal states require neural interactions across a hierarchy of timescales. However, most studies thus have focused on neural activity in a single frequency range or on a restricted set of brain regions. Here we provide evidence for cooperative spatiotemporal dynamics of slow and fast EEG signals during perceptual decision making at the single-trial level. Participants performed three masked two-choice decision tasks, one each with numerical, verbal, or figural content. Decrements in posterior $\alpha$ power $(8-14 \mathrm{~Hz})$ were paralleled by increments in high-frequency $(>30 \mathrm{~Hz})$ signal entropy in trials demanding active sensory processing. Simultaneously, frontocentral $\theta$ power $(4-7 \mathrm{~Hz})$ increased, indicating evidence integration. The coordinated $\alpha / \theta$ dynamics were tightly linked to decision speed and remarkably similar across tasks, suggesting a domain-general mechanism. In sum, we demonstrate an inverse association between decision-related changes in widespread low-frequency power and local high-frequency entropy. The cooperation among mechanisms captured by these changes enhances the informational density of neural response patterns and qualifies as a neural coding system in the service of perceptual decision making.

Key words: decision making; EEG; entropy; neural oscillations; single-trial analyses; synchronization

\section{Introduction}

Temporally synchronized neural firing patterns are advantageous for efficiently representing (Von der Malsburg, 1981; Gray and Singer, 1989) and transmitting (Fries, 2005) information within and between neural assemblies (for recent reviews, compare Buzsáki, 2006; Wang, 2010). However, computational (e.g., Rolls et al., 2003), empirical (e.g., Chalk et al., 2010; Schneidman et al., 2011), and conceptual accounts (Hanslmayr et al., 2012) hold that neural firing rates are more redundant when neural

\footnotetext{
Received Sept. 5, 2013; revised April 3, 2014; accepted April 5, 2014.
}

Author contributions: F.S., M.L., and U.L. designed research; M.W.-B. and C.C. performed research; M.W.-B. contributed unpublished reagents/analytic tools; M.W.-B. and T.H.G. analyzed data; M.W.-B., T.H.G., F.S., M.L., and U.L. wrote the paper.

This work was supported by the Max Planck Society (including the Innovation Fund Grant M.FE.A.BILD0005), the Sofja Kovalevskaja Award to M.L., administered by the Alexander von Humboldt Foundation and donated by the German Federal Ministry for Education and Research, the German Research Foundation (Deutsche Forschungsgemeinschaft KFG 163), and the German Federal Ministry for Education and Research [Center for Advanced Imaging CAI]. U.L. was supported by the Deutsche Forschungsgemeinschaft Gottfried Wilhelm Leibniz Award. We thank Douglas Garrett for valuable discussions about the measurement of entropy; Myriam Sander for critical comments on an earlier version of the manuscript; and Colin Bauer, Annette Brose, and all research assistants involved in data collection.

The authors declare no competing financial interests.

Correspondence should be addressed to Dr. Markus Werkle-Bergner, Center for Lifespan Psychology, Max Planck Institute for Human Development, Lentzeallee 94, 14195 Berlin, Germany. E-mail: werkle@mpib-berlin.mpg.de.

DOI:10.1523/JNEUROSCI.3801-13.2014

Copyright $\odot 2014$ the authors $\quad 0270-6474 / 14 / 348519-10 \$ 15.00 / 0$ synchronization is increased. The latter observation seems to contradict the claim that synchronized firing patterns improve information representation and transfer. Nevertheless, the two positions can be reconciled by assigning different roles to slow $(<20 \mathrm{~Hz})$ versus fast $(>30 \mathrm{~Hz})$ neural activity (von Stein and Sarnthein, 2000; Schroeder and Lakatos, 2009). The exact temporal interplay between slow rhythms and fast neural firing is well suited to represent stimulus-specific information (Sauseng et al., 2009; Whittingstall and Logothetis, 2009; e.g., Axmacher et al., 2010). Furthermore, population activity, such as measured by local field potentials or EEG, and single-neuron firing patterns may convey independent sources of information about visual inputs (Belitski et al., 2008; Montemurro et al., 2008). Hence, different neural codes can be expressed over a wide range of timescales and might be advantageous for encoding complementary information, ultimately enhancing the informational density of activity patterns (e.g., Panzeri et al., 2010).

Reaching decisions about action alternatives based on information from the environment is an important higher level cognitive function (Lee, 2013). In this context, the term "perceptual decision making" refers to the process of transforming sensory signals into a percept that is closely linked to an associated response (Shadlen and Newsome, 2001; Gross and Ploner, 2009). To decide between alternative behavioral responses, lower level 
sensory regions need to represent evidence about the identity of a given percept (e.g., Hebart et al., 2012). In addition, the sensory signal needs to be accumulated and compared against evidence for decision alternatives (Ratcliff, 1978). The latter probably involves higher-level cortical regions (e.g., Heekeren et al., 2004). Hence, the decision for one or the other action based on available sensory evidence requires the interaction of a widespread neural network comprising sensory-specific areas, as well as control regions in the parietal and prefrontal cortex in conjunction with motor areas (for an overview, see Heekeren et al., 2008). Accordingly, previous results suggest that accumulation of sensory evidence in support of behavioral decisions can be considered a broadband phenomenon resulting in neural activity patterns across various frequency ranges (e.g., Bauer et al., 2006; Donner et al., 2007, 2009; van Vugt et al., 2012). Hence, perceptual decision making presents a paradigmatic case to study the cooperative dynamics of rhythmic neural activity across frequency ranges and brain networks.

Accordingly, the present study, aimed to unravel the singletrial mechanisms by which temporally structured low-frequency neural activity patterns interact with local increases in neural firing activity, approximated as the entropy of high-pass filtered (>30 Hz) EEG traces (see, e.g., Buzsáki et al., 2012), to support processing of sensory information about decision alternatives.

\section{Materials and Methods}

Participants. The current report used data from a subsample of the COGITO study (compare Schmiedek et al., 2010), conducted at the Max Planck Institute for Human Development (Berlin). Participants were recruited through newspaper advertisements, word-of-mouth recommendation, and flyers circulated in Berlin, for a longitudinal study on training and day-to-day variability of cognitive performance. The ethics committee of the Max Planck Institute for Human Development approved the study. All participants gave written informed consent.

In the COGITO study, a relatively large sample of individuals in an intervention group $(n=204)$ practiced a broad battery of perceptual speed, working memory, and episodic memory tasks for over 100 one hour sessions. A no-contact control group $(n=83)$ took part in an extensive cognitive assessment before (pretest) and after (posttest) the $100 \mathrm{~d}$ of cognitive training only. Approximately $30 \%$ of the parent sample also volunteered and were eligible for participating in EEG recordings that were conducted in the context of the pretest and post-test assessments. Extensive descriptives for the EEG subsample as well as comparisons with the COGITO parent sample were provided previously (Grandy et al., 2013a, b).

To be eligible, participants had to have normal or corrected-to-normal vision and be right-handed. In addition, they had to report not to suffer from any of the following conditions: cardiovascular disease, except for treated hypertension; diabetes; neurological or psychiatric conditions; use of antiseizure or antidepressant drugs; or drug or alcohol abuse. For the present report, we analyzed data from the pretest assessment. Hence, the sample size could be increased by aggregating across experimental and control groups $(N=40,21$ female; mean \pm SD age, $25.17 \pm 2.81$ years).

Tasks and stimuli. Behavioral performance in the present report is derived from choice reaction time (CRT) tasks that were administered during EEG recordings. Participants performed three versions of the task: numerical, verbal, and figural (for a schematic of stimuli, see Fig. 1). In the numerical version, they had to indicate whether a presented digit was odd or even, in the verbal version, whether a presented letter was a consonant or a vowel, and in the figural version, whether the presented figure was symmetric or asymmetric with respect to a vertical axis. The three CRT tasks were based on the same stimulus layout: the seven lines of the number " 8 " as displayed on pocket calculators (Fig. 1). Target stimuli were masked with a configuration that combined this "calculator 8 " with extending lines in all 10 possible directions. The stimuli were

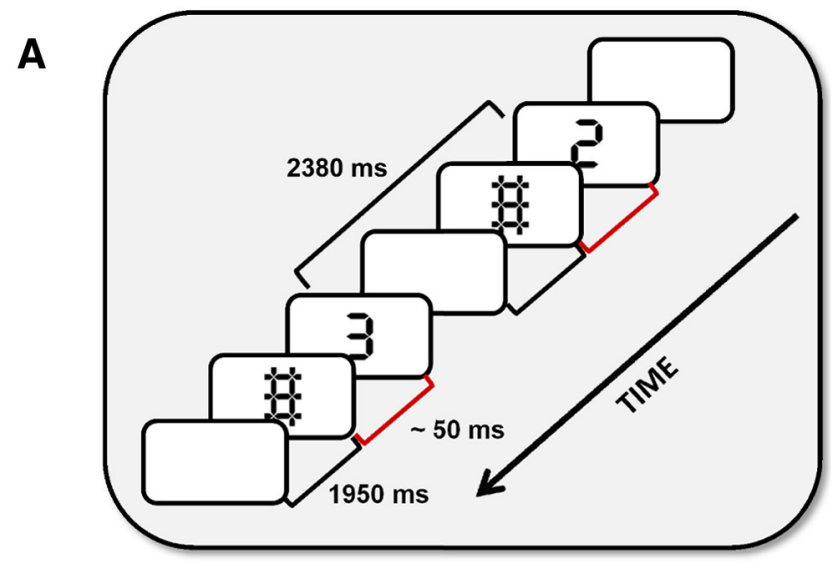

\section{B}

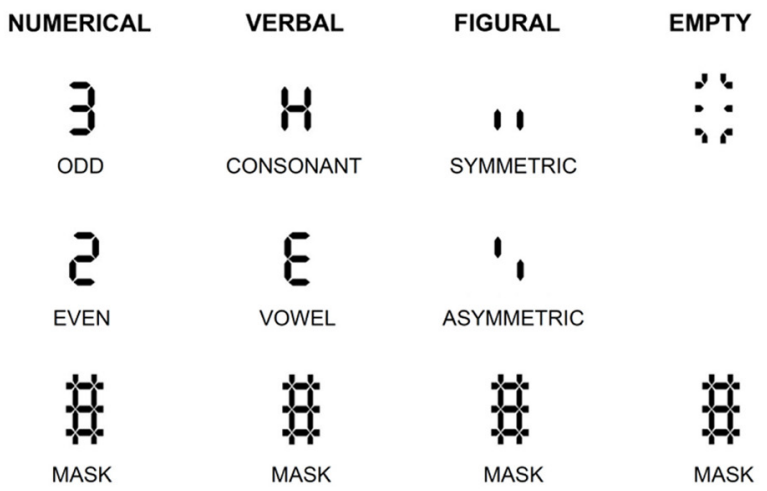

Figure 1. Schematic illustration of trial design $(\boldsymbol{A})$, as well as the stimuli and conditions implemented in the numerical, verbal, and figural choice reaction tasks $(\boldsymbol{B})$.

Table 1. Summary of behavioral performance ${ }^{a}$

\begin{tabular}{llll}
\hline & & \multicolumn{2}{l}{ Median RT (ms) } \\
\cline { 2 - 4 } & Accuracy (\%): STIM & Correct & Incorrect \\
\hline Numerical & $92.6 \pm 1.1$ & $704 \pm 18$ & $919 \pm 43$ \\
Verbal & $83.4 \pm 1.7$ & $737 \pm 20$ & $921 \pm 28$ \\
Figural & $94.4 \pm 0.8$ & $667 \pm 15$ & $803 \pm 24$ \\
\hline
\end{tabular}

${ }^{a}$ Values are group mean $\pm \mathrm{SE} ; \mathrm{N}=40$ participants.

presented on a 17 inch LCD screen with a frame rate of $60 \mathrm{~Hz}$ for $\sim 50 \mathrm{~ms}$ (i.e., 3 frames) followed by a mask for $1950 \mathrm{~ms}$. The interstimulus interval was set to $2380 \mathrm{~ms}$. Additionally, one-third of the trials consisted of "empty" (null) stimuli; that is, only an empty frame was shown for $50 \mathrm{~ms}$ followed by the mask. Each version consisted of 192 stimuli plus 96 null stimuli, split into 12 blocks each, which were presented in random order. Participants were instructed to respond as quickly and accurately as possible to which category the stimulus belonged by pressing a button on the keyboard with either their right index or right ring finger. They were asked not to respond and wait for the next stimulus when a null stimulus was presented. Stimulus presentation and recording of behavioral responses were controlled with E-Prime 1.2 software (Psychology Software Tools).

EEG data acquisition. EEG was recorded continuously with BrainAmp amplifiers (Brain Products) from $64 \mathrm{Ag} / \mathrm{AgCl}$ electrodes. Sixty scalp electrodes embedded in an elastic cap (EASYCAP) were organized according to the $10 \%$ system (compare Oostenveld and Praamstra, 2001). AFz served as ground. Two electrodes were placed on the outer canthi (horizontal EOG) and one electrode below the left eye (vertical EOG) to monitor eye movements. During recording, all electrodes were referenced to the right mastoid electrode, whereas the left mastoid electrode was recorded as an additional channel. Electrode impedances were main- 

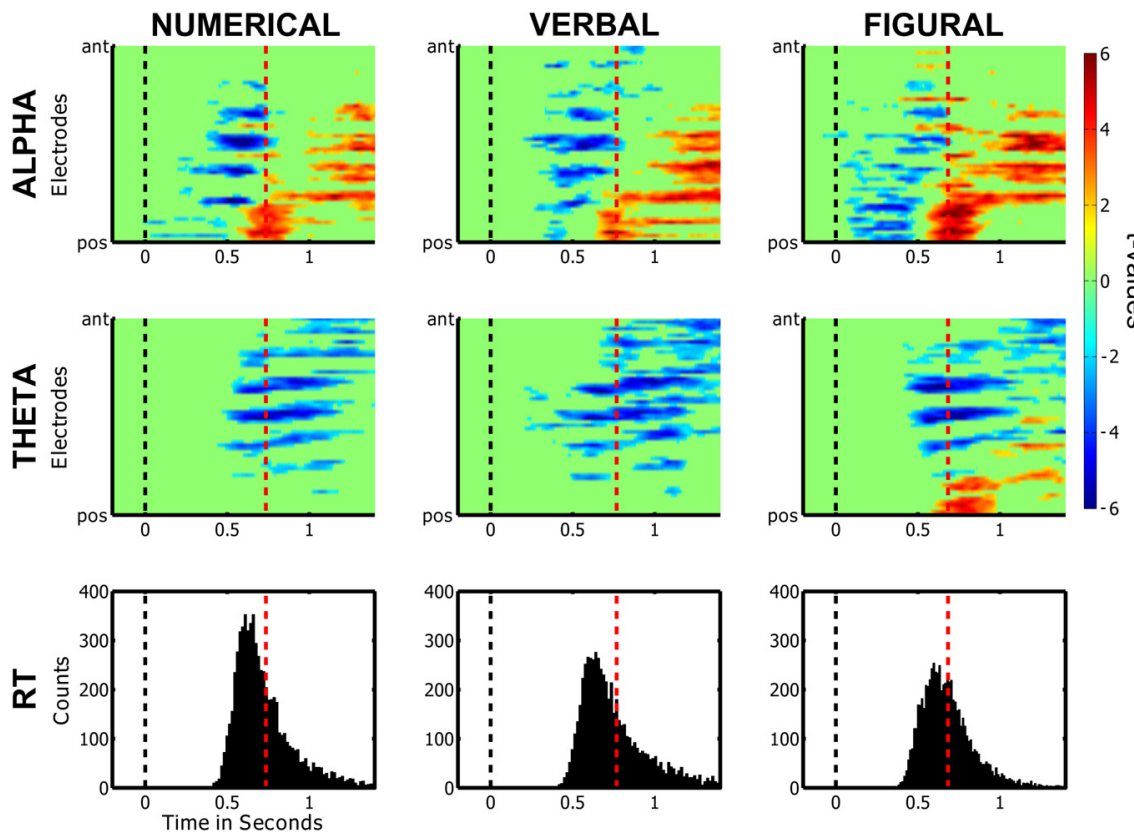

Figure 2. Summary of results for single-trial correlation analyses, separately for each CRT (columns from left to right: numerical, verbal, and figural task). The color-coded images represent electrode ( $y$-axis) time regions ( $x$-axis) with reliable associations (group level analysis; masked at $p<0.05$, cluster level) between oscillatory power in the $\alpha$ (top row) or $\theta$ frequency (middle row) range and single-trial RT distributions (RT histograms, bottom row). Vertical black dotted line indicates stimulus onset; red dotted line indicates the median RT across trials and participants. For each color image, the electrodes are approximately ordered from anterior (top) to posterior (bottom) locations. The color scale represents $t$ values. Warm colors represent a positive association (i.e., higher power associated with shorter RT); cold colors represent a negative relationship (i.e., higher power associated with longer RT).

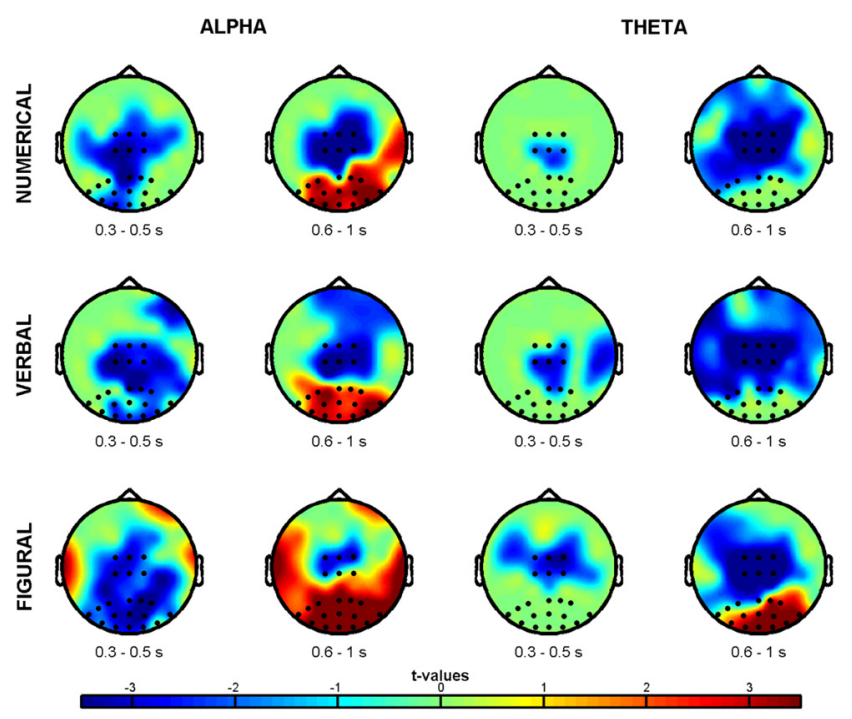

Figure 3. Topographical distribution of reliable single-trial power-RT associations for each CRT (rows from top to bottom: numerical, verbal, and figural task) within the $\alpha$ (two left-most columns) and $\theta$ frequency ranges (two right-most columns). The topographical maps representmean $t$ values averaged across two representative time windows (early: $0.3-0.5 \mathrm{~s}$; late: $0.6-01 \mathrm{~s}$ poststimulus). Only reliable electrode time points (group level analysis; masked at $p<0.05$, duster level) were included in the averages within the respective time window. Warm colors represent a positive association (i.e., higher power associated with shorter RT); cold colors represent a negative relationship (i.e., higher power associated with longer RT). The small black dots indicate the central ( $\mathrm{FCl}, \mathrm{FCZ}, \mathrm{FC}, \mathrm{C1}, \mathrm{CZ}, \mathrm{C}$ ) and posterior ( $\mathrm{P7}$, P5, P3, Pz, P2, P4, P8, P07, $\mathrm{PO} 3, \mathrm{POZ}, \mathrm{PO4}, \mathrm{PO8}, 01,0 \mathrm{z}, \mathrm{O}_{2}$ ) electrode regions of interest used for further analyses ofsignal powerchanges in the $\alpha$ and $\theta$ frequency range.

tained $<5 \mathrm{k} \Omega$ before recording. The EEG was recorded with an analog pass band of $0.1-250 \mathrm{~Hz}$ and digitized with a sampling rate of $1 \mathrm{kHz}$.

EEG data preprocessing. Preprocessing and analysis of EEG data were performed using the EEGLAB (Delorme and Makeig, 2004) and Field-
Trip toolboxes (developed at the F.C. Donders Centre for Cognitive Neuroimaging, Nijmegen, The Netherlands; http://fieldtrip. fcdonders.nl/) (Oostenveld et al., 2011), as well as custom-written MATLAB (MathWorks) code. EEG data were rereferenced to mathematically linked mastoids, filtered with a fourth-order Butterworth filter and a pass band of $0.5-100 \mathrm{~Hz}$, and segmented into epochs of $3.5 \mathrm{~s}$ around stimulus onset $(-1$ to $2.5 \mathrm{~s}$ ). Segments were visually inspected, and all epochs containing artifacts other than eye blinks and eye movements were excluded from further analyses. After manual artifact rejection, an extended infomax-independent component analysis (Bell and Sejnowski, 1995) was conducted to correct for eye blinks and movements. Afterward and to attenuate effects resulting from volume conduction, Laplacian current source density (CSD) (Perrin et al., 1989) was calculated for all channels of the artifact-controlled EEG recordings (order of splines: 4; maximum degree of Legendre polynomials: $10 ; \lambda$ : 1e-5) using the CSD-toolbox (Kayser and Tenke, 2006; Kayser, 2009). Timevarying power and phase information for each trial and electrode were extracted by applying the Hilbert-transform to bandpass filtered CSD signals (fourth-order Butterworth filter) in the $\alpha(8-14 \mathrm{~Hz})$ and $\theta(4-7 \mathrm{~Hz})$ range (Le Van Quyen et al., 2001). To assure comparability of changes in power across individuals, frequency bands, and tasks, each trial was normalized with regard to a prestimulus baseline $(-0.2$ to $0 \mathrm{~s})$. Afterward, the oscillatory power $(\mathrm{P})$ in each trial was expressed as a relative signal change with regard to the prestimulus baseline (e.g., Pfurtscheller and Aranibar, 1977). For each electrode $(e)$ and time point $(t)$ in trial $j$, the relative signal change was computed as follows:

$$
R S C_{j . t . e}=\frac{P_{j, t, e}-B L_{j, e}}{B L_{j, e}}
$$

EEG single-trial analysis of oscillatory power. To reveal the within-trial dynamics of rhythmic neural activity patterns for each individual (e.g., Rousselet et al., 2011; Cohen and Cavanagh, 2011), single-trial correlation analyses were performed. More precisely, we computed correlations between reaction time (RT) and the relative change in signal power at each point in electrode-time space for each participant. As normality cannot be guaranteed for power and derived measures (Kiebel et al., 2005), robust Spearman correlations were used (Rousselet and Pernet, 2012). The resulting correlation coefficients $(\rho)$ were converted to $z$-scores by means of the Fisher-Z transform. The resulting $z$-values represent a first level statistic for testing the strength of the association between relative power changes and RT at each electrode-time point within individuals (e.g., van Dijk et al., 2010; Werkle-Bergner et al., 2012 for similar approaches)

Only artifact-free trials with correct responses were entered in the single-trial analyses. Furthermore, trials with response times exceeding a threshold of $3 \mathrm{SD}$ of the distribution for a given task were excluded from the analysis. Detection of RT outliers was done iteratively; that is, after exclusion of outlier trials in step $i-1$, the mean and SD were recomputed for the remaining trials on step $i$ and again checked for trials exceeding the threshold. The procedure stopped when no further outliers were detected.

Time-varying entropy analysis. The amount of information about a given stimulus contained in a neural response pattern can be quantified by measures derived from information theory (Quian Quiroga and Panzeri, 2009). The amount of information conveyed in a time-varying signal can be estimated by measuring the uncertainty about the values that 
might be taken by the random variable underlying the time series. The Shannon Entropy $H(T)$ of the distribution $P(v)$ of values $v$ in a given time-frame $T$ (e.g., Bishop, 2006) provides such as measure:

$$
H(T)=-\sum_{v} P(v) \log _{2}(P(v))
$$

To estimate changes in information content within a given trial and electrode, the entropy measure was calculated within sliding time windows of 256 points (i.e., $256 \mathrm{~ms}$ ) centered at the time point of interest, between -0.2 and $1.4 \mathrm{~s}$, for every available sample point (i.e., step size of $1 \mathrm{~ms}$ ). The stability of entropy estimates for short time windows has been demonstrated previously (Bezerianos et al., 2003).

The entropy of a signal is dependent on the range of the distribution $P(v)$, in a way that sharply peaked distributions tend toward lower entropy compared with widely spread distributions with a broad range of values (Bishop, 2006). One may argue that timevarying changes in entropy simply reflect signal compression/expansion because of variability in the high-amplitude low-frequency components that typically dominate the EEG signal, as reflected in the ubiquitous $1 / \mathrm{f}^{\mathrm{a}}$ frequency spectrum (e.g., He et al., 2010). Moreover, simultaneous intracranial and EEG recordings in monkeys have revealed that neural firing activity, reflecting stimulus-specific information, is strongly correlated with low-amplitude highfrequency EEG activity (Whittingstall and Logothetis, 2009). Hence, high-frequency activity in the scalp EEG can be regarded as a viable noninvasive approximation to modulations of local neural firing activity (Buzsáki et al., 2012). Therefore, preprocessed (see description above) artifact-free CSD-transformed (Perrin et al., 1989; Kayser and Tenke, 2006; Kayser, 2009) single-trial EEG traces were highpass filtered (cutoff frequency: $30 \mathrm{~Hz}$; fourth-order Butterworth filter) to estimate changes in information content independent of the fluctuations in the $\alpha$ and $\theta$ frequency ranges.

For each single trial, the poststimulus entropy $\left(E^{p s t}\right)$ was compared against prestimulus entropy $\left(E^{p r e} ; t=[-0.2,0]\right)$, by converting poststimulus estimates to $z$-values. For each electrode $(e)$ and time point $(t)$ in trial $j$, the $z$-values were computed as follows:

$$
z_{j . t . e}=\frac{E_{j, t, e}^{p s t}-\operatorname{mean}\left(E_{j, e}^{p r e}\right)}{s t d\left(E_{j, e}^{p r e}\right)}
$$

The $z$-values represent a level 1 statistic, reflecting the poststimulus change in entropy, controlling for possible electrode and trial-specific noise confounds.

Comparison of stimulus-present versus stimulus-absent conditions. To reveal neural mechanisms specific to evidence accumulation, trials that required a perceptual decision (STIM; stimulus present) were compared against trials were no accumulation was possible because of the absence of a stimulus (NOSTIM). Similar to the correlation analyses, a first level statistic was computed by comparing STIM versus NOSTIM trials within participants by means of independent-samples $t$ tests at each electrode time point. The resulting $t$-scores were converted to $z$-values. This set of analyses was primarily motivated by the temporal dynamics over frontocentral and occipitoparietal electrode regions identified in the single-trial correlation analyses (for definition of electrode clusters, see Results). Accordingly, the $z$-values were averaged across electrodes and subjected to second-level analyses across time. STIM and NOSTIM conditions were compared for measures of oscillatory power in the $\alpha$ and $\theta$ frequency range.
ALPHA
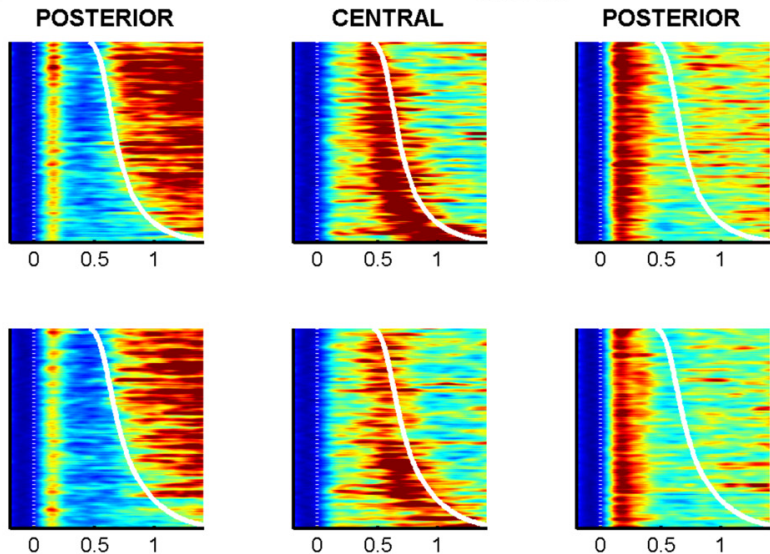

THETA
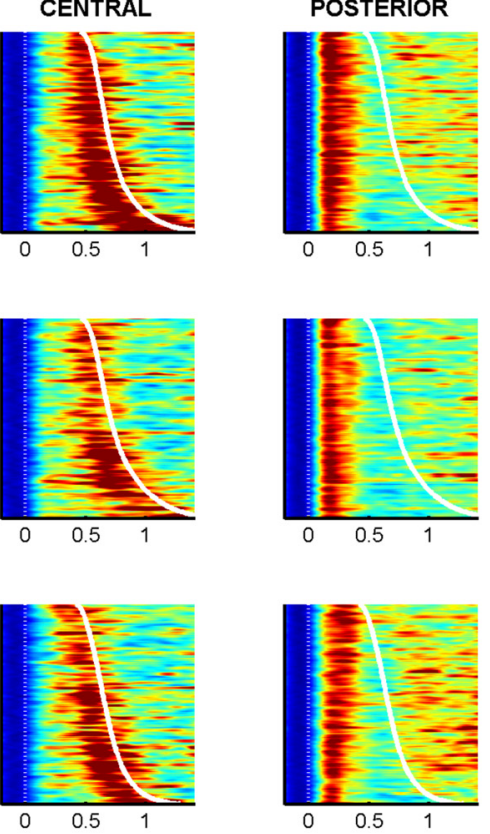

t-values

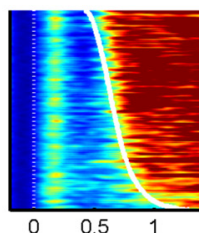

0.5

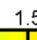

2

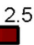
and $\theta$ frequency range (the two right-most columns). The $y$-axis for each plot represents the individual trials sorted according to $R T$ , the images were smoothed with a 100 trial-wide boxcar function from top to bottom after sorting. In these plots, each horizontal row represents one single trial. By comparing the same row (i.e., trial) from left to right within a given task condition, the dynamics of the same trial across regions and frequency ranges is revealed.

EEG group level analyses of power and entropy: cluster-based permutation tests. To assess the reliability of effects derived from the single-trial analyses at the group level, cluster-based permutation tests as implemented in FieldTrip (Maris and Oostenveld, 2007) were used. More precisely, for analyses across the entire scalp, at each electrode time point, the individual $z$-maps were subjected to a mass-univariate cluster-based $t$ test (testing for significant differences from zero, two-sided, 1000 iterations; minimum number of neighboring channels per cluster $=2$, neighborhood extent $=40 \mathrm{~mm}$; cluster entry level: $p<0.01$; clustersignificance level: $p<0.05)$. In essence, this procedure identifies timeelectrode clusters for which the assumption of no association between power and RT can be rejected at the group level, and effectively controls for multiple comparisons (Maris and Oostenveld, 2007; Groppe et al., 2011). Similarly, for analyses comparing the time course at electrode regions of interest, clusters were identified as neighboring time points for which the difference between conditions, reflected in $z$-scores, was reliably different from zero at the group level (two-sided, 1000 iterations; cluster entry level: $p<0.01$; cluster significance level: $p<0.05)$. The same procedure was used to assess the reliability of poststimulus changes in high-frequency entropy at the group level.

\section{Results}

\section{Behavioral results}

Overall, participants were highly efficient in detecting the stimulus-absent (NOSTIM) trials reflected in a mean accuracy of $99.9 \%$ (SE 0.02). A summary of the behavioral performance in stimulus present (STIM) trials separately for the three task conditions is provided in Table 1.

The decision accuracy, measured as the percentage of correct responses across all STIM trials of a given task condition, varied 


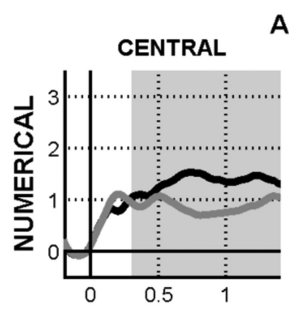

ALPHA
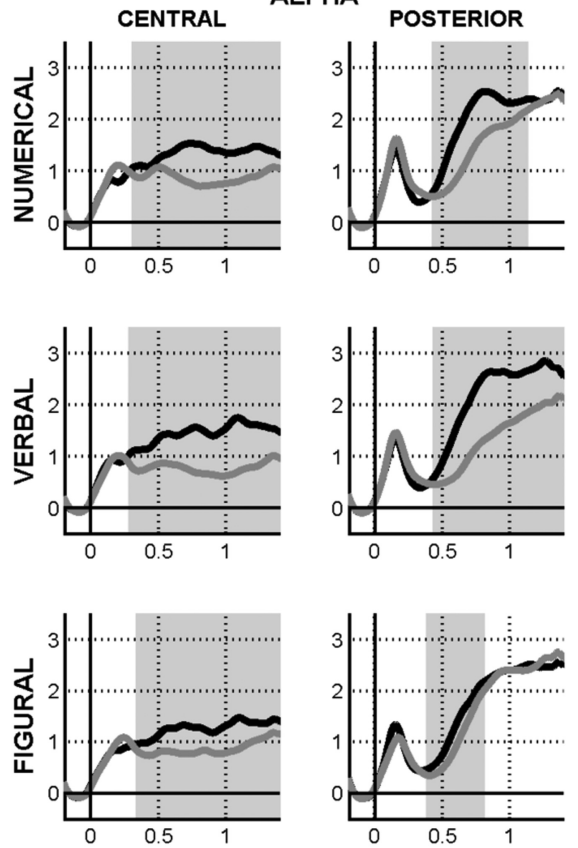

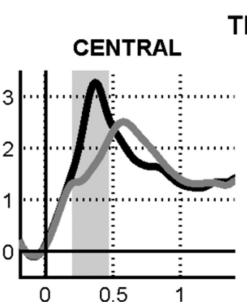

THETA
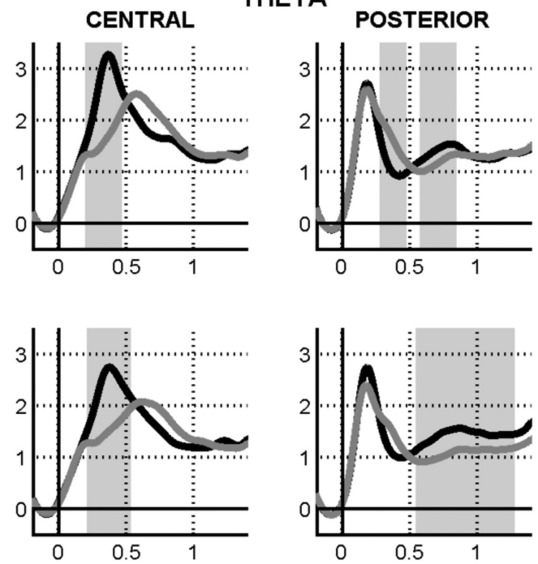

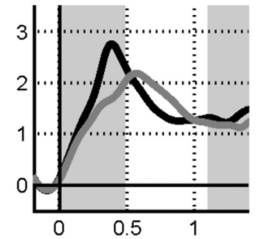

Figure 5. Time-varying changes in signal amplitude for stimulus-present (STIM, dark gray lines) and stimulus-absent (NOSTIM, black lines) conditions. The grand-average relative changes in signal amplitude ( $y$-axis) for central and posterior electrode regions of interest (for details, see Fig. 3) are plotted separately for each task (rows from top to bottom: numerical, verbal, figural) in the $\alpha$ (the two left-most columns) and $\theta$ frequency range (the two right-most columns). The gray shaded patches represent time windows for which the cluster-based permutation tests revealed reliable differences (group level analysis; $p<0.05$, cluster level) between STIM and NOSTIM conditions. The $x$-axis represents time (in seconds) relative to stimulus onset.
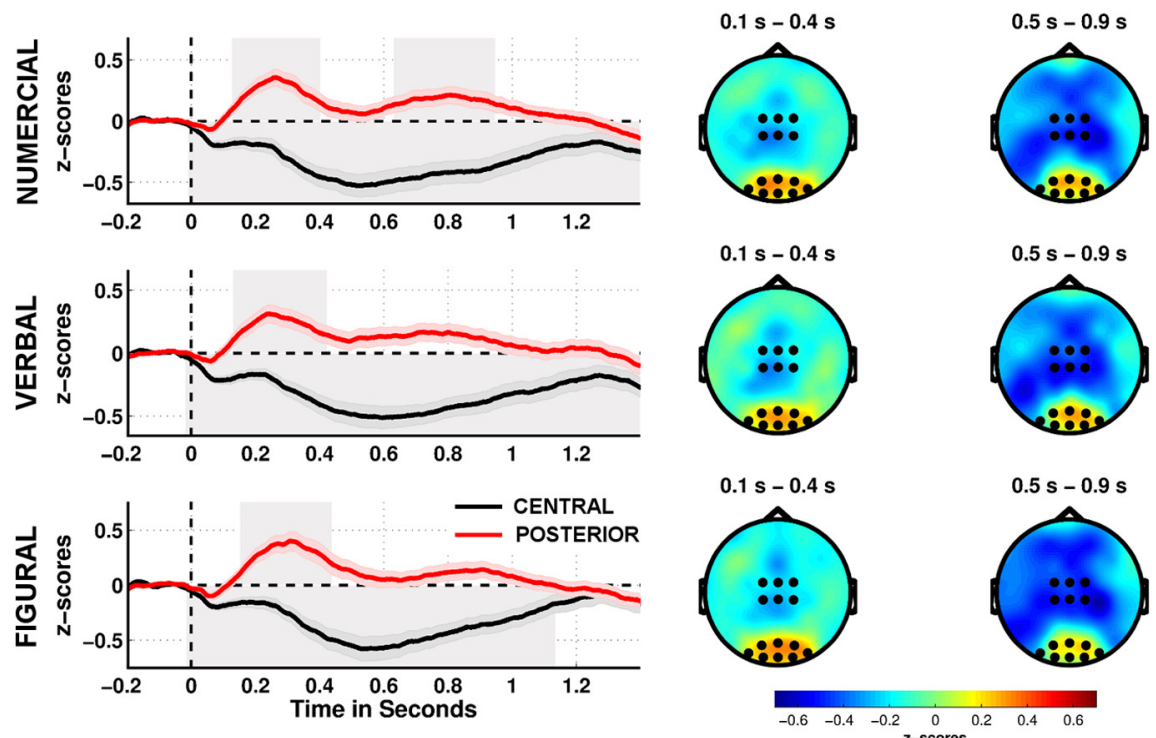

Figure 6. Time-varying changes in signal entropy $(>30 \mathrm{~Hz})$ for the stimulus-present condition. Each row presents the results for a given task (from top to bottom: numerical, verbal, figural). The time evolution of changes in entropy, expressed in $z$-values ( $y$-axis), is shown on the left for a central (black line) and a posterior (red line) electrode region of interest. The shaded black/red patches surrounding the thick lines represent $\pm 2 \mathrm{SE}$. The light gray shaded patches in the back represent time windows for which the cluster-based permutation tests revealed reliable changes in signal entropy compared with baseline (group level analysis; $p<$ 0.05 , cluster level). The significant time windows for the central region of interest were long-lasting and only in the negative direction, for the posterior region comparably short-lasting and exclusively in the positive direction. The $x$-axis represents time (in seconds) relative to stimulus onset. The topographical distribution of stimulus-locked changes in signal entropy is illustrated for two representative time windows (early: $0.1-0.4 \mathrm{~s}$; late: $0.5-0.9 \mathrm{~s}$ poststimulus) in the middle and right-most column. Small black dots indicate the central ( $\mathrm{FCl} 1, \mathrm{FCZ}, \mathrm{FC2}, \mathrm{C1}, \mathrm{Cz}, \mathrm{C} 2)$ and posterior (P07, P03, POz, P04, P08, 01, 0z, $\mathrm{O}_{2}$ ) electrode regions of interest used for analyses. The early posterior increase and the later decrease over central regions are clearly visible. across content domains $\left(F_{(2,78)}=37.5\right.$, $p<0.05)$ as revealed by an one-way repeated-measures ANOVA with the factor task type (numerical vs figural vs verbal). The accuracy in the verbal task was lower compared with both the numerical $\left(t_{(39)}=7.9, p<0.0167\right)$ as well as the figural task $\left(t_{(39)}=6.8, p<0.0167\right)$, whereas the latter two did not differ $\left(t_{(39)}=\right.$ $1.49, p>0.14)$.

The speed of the decision process was measured as the median RT across all STIM trials for a given task condition, separately for correct and incorrect responses. A two-way repeated-measures ANOVA with factors task type (numerical vs figural vs verbal) and response type (correct vs incorrect) revealed reliable main effects (task type: $F_{(2,78)}=11.9, p<$ 0.05 ; response type: $F_{(1,39)}=80.6, p<$ $0.05)$, although the interaction did not reach significance $\left(F_{(2,78)}=2.5, p>0.08\right)$. Overall, correct responses (mean $\pm \mathrm{SD}$, $702 \pm 10 \mathrm{~ms}$ ) were faster than incorrect ones (mean $\pm \mathrm{SD}, 881 \pm 19 \mathrm{~ms}$ ). Decisions were taken faster in the figural compared with both the numerical $\left(t_{(39)}=3.1\right.$, $p<0.0167)$ and the verbal task $\left(t_{(39)}=\right.$ $5.7, p<0.0167)$, whereas response speed was comparable for the latter $\left(t_{(39)}=0.9\right.$, $p>0.39$ ).

Single-trial analyses of oscillatory power Previous reports point to frontocentral $\theta$ oscillations as likely neural implementation of general accumulators in decision making tasks (van Vugt et al., 2012; Guitart-Masip et al., 2013). But frontocentral $\theta$ networks do not work in isolation; they depend on the availability of task-related sensory information. Thereby both stimulus characteristics (compare Philiastides and Sajda, 2006, 2007) and the appropriate top-down states (e.g., Capotosto et al., 2009) determine the quality of available sensory information. In this regard, the dynamics of $\alpha$ band activity surrounding stimulus onsets carries information about controlled sensory processing states (Busch et al., 2009; Mathewson et al., 2009; Romei et al., 2010; Haegens et al., 2011a). We reasoned that fast decisions should be supported by efficient generation of sensory evidence about decision alternatives. As synchronized states of low-frequency neural activity are generally seen to reflect local inhibition (e.g., Klimesch et al., 2007), we expected decision speed to be related to increased signal entropy (e.g., Hanslmayr et al., 2012) as indexed by the duration of desynchronized low-frequency states over sensory-specific regions. 
Figure 2 depicts the electrode-time points for which the single-trial correlation analyses resulted in reliable associations between changes in signal power and RT at the group level for the $\alpha$ and $\theta$ band, respectively. With regard to the $\alpha$ frequency band, for all three tasks, one significant positive and one significant negative cluster were obtained, respectively ( $p<0.05$, cluster level). For the $\theta$ band, only one negative cluster was obtained, except for the figural task, where an additional positive cluster reached significance $(p<0.05$, cluster level).

The topographical distribution of the effects is illustrated in Figure 3. Overall, the pattern was qualitatively comparable across all tasks. A larger signal power compared with baseline was associated with slower response times (negative clusters) at electrodes over frontocentral locations for both $\alpha$ and $\theta$ oscillations. The time course of these effects differed between the two frequency bands. In the $\alpha$ band, the time period during which lower power was associated with faster decisions lasted from $\sim 350 \mathrm{~ms}$ to $\sim 600$ $\mathrm{ms}$ after stimulus onset; in the $\theta$ band, the corresponding effect was observed later and persisted over a longer time period $(\sim 450-1400 \mathrm{~ms})$. In contrast, lower poststimulus power was associated with slower decisions for a cluster of electrodes located over parietal regions. This cluster was primarily observed in the $\alpha$ band, and extended from $\sim 550$ to $1400 \mathrm{~ms}$ after stimulus onset. Only for the figural task, an additional positive cluster was observed in the $\theta$ range.

A close inspection of the temporal evolution of the group effects suggests an interactive within-trial dynamic between $\alpha$ and $\theta$ rhythms (Fig. 2). The negative $\alpha$ cluster appears most pronounced before execution of the manual response, given that it is mainly expressed before the median RT (marked by the red dotted line). Conversely, the positive $\alpha$ and negative $\theta$ clusters emerge simultaneously past the median RT.

To further unpack the underlying within-trial dynamics of $\alpha$ and $\theta$ oscillations, mean signal changes for a representative cen$\operatorname{tral}(\mathrm{FC} 1, \mathrm{FCz}, \mathrm{FC} 2, \mathrm{C1}, \mathrm{Cz}, \mathrm{C} 2)$ and posterior (P7, P5, P3, Pz, P2, P4, P8, PO7, PO3, POz, PO4, PO8, O1, Oz, O2) cluster were computed for each trial (Fig. 3, highlighted electrode locations). Afterward, single trials were sorted across all participants according to their RT (e.g., Makeig et al., 2002, 2004).

As shown in Figure 4, the RT-related within-trial dynamics of $\alpha$ and $\theta$ oscillations was similar across tasks. A strong stimulus-induced power increase (warm colors) was observed within the first $300 \mathrm{~ms}$ over posterior recording locations for both $\alpha$ and $\theta$ frequency ranges. This power increase was unrelated to speed of responding and possibly reflects processes related to stimulus encoding (Philiastides and Sajda, 2006; Philiastides et al., 2006). In the $\alpha$ band, the initial power increase at posterior electrodes was followed by a power decrease (e.g., Pfurtscheller and Lopes da Silva, 1999; Hanslmayr et al., 2012) ( $\alpha$ desynchronization) that extended until response execution and rebounded afterward. Hence, the relation between stronger power increase and shorter RT observed in the single-trial correlation analyses can be explained by an earlier termination of the $\alpha$ desynchronization and a faster resynchronization afterward. Conversely, the observation of an association between prolonged RT and a relative increase in signal power was reflected in a steady increase of oscillatory neural activity until response execution over central regions that breaks down afterward (van Vugt et al., 2012). Of note, the strong increase in oscillatory $\theta$ activity over central regions was taking place simultaneously with the power decreases in $\alpha$ activity over posterior regions (Fig. 5).
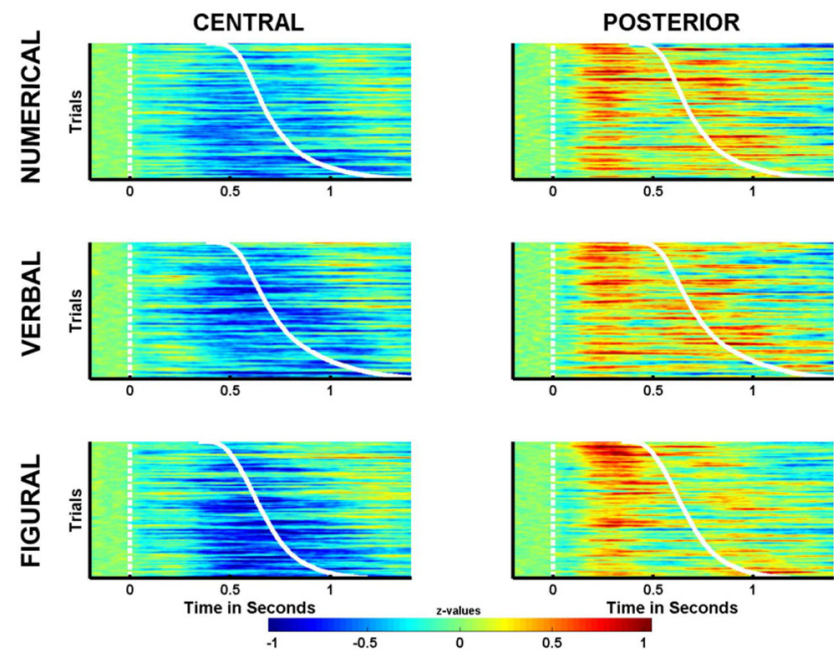

Figure 7. Single-trial dynamics of entropy changes illustrated for selected electrode regions of interest (for details on electrode selection, see Fig. 6). The left column represents single-trial entropy changes (expressed in z-values) over central recording locations for the numerical (top row), verbal (middle row), and figural task (bottom row). The same information for posterior electrode sites is illustrated in the right column. The $y$-axis for each plot represents the individual trials sorted according to RT from top to bottom. The S-shaped solid white line indicates the respective RT for each trial. The dotted white line indicates stimulus onset. The color scale indicates the relative change in high-frequency signal entropy with regard to a prestimulus baseline expressed in $z$-values (see Materials and Methods). Each plot represents data from 6642 trials for the numerical, 5959 trials for the verbal, and 6780 trials for the figural task. For visualization, the images were smoothed with a 100 trial-wide boxcar function from top to bottom after sorting. Each horizontal row represents one single trial. The decrease in entropy over central regions is maximal around the RT and varies with it (i.e., slightly S-shaped). By contrast, the initial increase in entropy over posterior recording sites is related to stimulus onset (i.e., rather parallel to the dashed white line indicating stimulus onset).

\section{Low-frequency EEG dynamics for stimulus-present versus stimulus-absent conditions}

To reveal the specificity of neural activity in the $\alpha$ and $\theta$ bands for evidence accumulation, trials that required a behavioral decision (stimulus present, STIM) were compared against trials that did not require evidence accumulation because of the absence of a task-relevant stimulus (stimulus absent, NOSTIM). The analysis was focused on those central and parietal recording locations that revealed robust associations between changes in signal power and individual RT distributions (see Fig. 3; description above).

The results revealed comparable differences in the time course of power changes between STIM and NOSTIM for all three CRTs (for a graphical summary, see Fig. 5). Within the $\alpha$ frequency range, the processing of stimulus-related information during STIM trials was associated with a lower increase in signal power over central regions ( $p<0.05$, cluster level), starting at $\sim 0.4 \mathrm{~s}$ after stimulus. Similarly, over posterior electrode sites, the absence of decision-related sensory information in NOSTIM trials was related to a shorter desynchronization and a faster rebound, reflected in lower signal power for STIM trials during the resynchronization phase ( $p<0.05$, cluster level).

For the $\theta$ frequency range, NOSTIM trials were associated with a stronger and earlier power increase over central locations reflected in reliably larger power changes compared with STIM trials $(p<0.05$, cluster level) in the first $0.5 \mathrm{~s}$ after stimulus onset. Only for the figural task, this difference was inverted in a later time window $(\sim 1.1-1.4 \mathrm{~s}$ after stimulus, $p<0.05$, cluster level $)$. For the posterior electrode cluster, STIM trials were associated with a delayed decrease in signal power in the numerical and figural task in a time window from $\sim 0.35$ to $0.5 \mathrm{~s}(p<0.05$, 
POSTERIOR
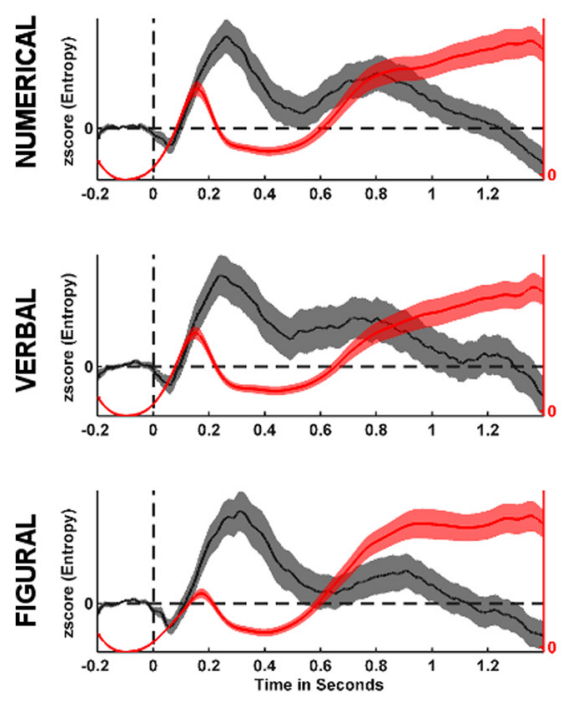

POWER
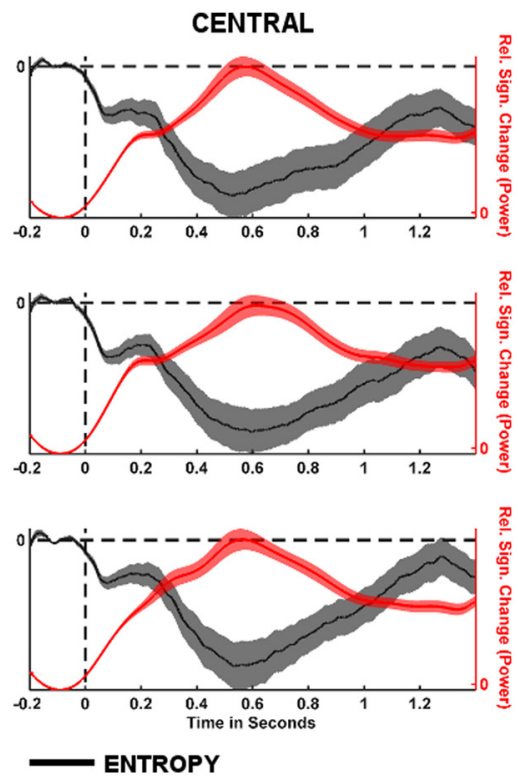

ENTROPY

Figure 8. Direct comparison of poststimulus changes in signal power (red) and high-frequency signal entropy (dark gray). The solid lines in each plot indicate the group average of each measure, whereas the surrounding red/gray shaded patches represent \pm 2 SE. The $y$-axis on the left (gray) represents changes in entropy with regard to a prestimulus baseline expressed in $z$-scores. The $y$-axis on the right represents the percentage change in signal power from baseline for posterior $\alpha$ (left column) and central $\theta$ (right column) activity. For the posterior electrode cluster, it becomes apparent that the peak in entropy increases follows the early stimulus-related peak in $\alpha$ power changes and is co-occurring with the initial half of the $\alpha$ desynchronization that follows. By contrast, for central recording locations, both the increase in $\theta$ activity as well as the decrease in high-frequency power reach their maximum or minimum, respectively, around the mean RT and slowly return to baseline levels thereafter.

cluster level). During later time windows ( $>0.5 \mathrm{~s})$, NOSTIM trials elicited larger power increases in the numerical and verbal task $(p<0.05$, cluster level).

\section{Changes of high-frequency signal entropy accompany low-frequency dynamics in opposing direction}

Finally, we addressed the prediction that states of synchronized or desynchronized local low-frequency activity should coincide with decreased/increased signal entropy (Hanslmayr et al., 2012). For this analysis, we examined whether reliable changes in entropy during the poststimulus time interval were found when compared with a prestimulus epoch $(-0.2$ to $0 \mathrm{~s})$. This was achieved by testing within-person $z$-values reflecting the change from prestimulus baseline by cluster-based permutation analyses on the group level for a central (FC1, FCz, FC2, C1, Cz, C2) and a posterior ( $\mathrm{PO} 7, \mathrm{PO} 3, \mathrm{POz}, \mathrm{PO} 4, \mathrm{PO} 8, \mathrm{O} 1, \mathrm{Oz}, \mathrm{O} 2$ ) electrode region of interest, respectively. The main results are summarized in Figure 6.

In all three tasks, the increase in $\theta$ power over central regions was paralleled by a long-lasting decrease in highfrequency signal entropy ( $p<0.05$, cluster level) that peaks around the mean RT. Inspection of single-trial dynamics (Fig. 7) indeed revealed a decrease of signal entropy that was maximally expressed around response execution and only slowly returned to baseline afterward.

For posterior recordings, locations a different picture emerged. Here, high-frequency signal entropy increased in an early time window $(\sim 0.15-0.4 \mathrm{~s})$ after stimulus onset in all three tasks ( $p<0.05$, cluster level). Only for the numerical task, a late cluster of signal entropy increases also was statistically reliable $(p<0.05$, cluster level). The single-trial dynamics of posterior entropy changes (Fig. 7) suggests that the reliable early increases reflect stimulus-related processing. A direct visual comparison of the temporal evolution of changes in posterior $\alpha$ power and high-frequency signal entropy (Fig. 8) shows that the increase in entropy sets in only after the initial increase in stimulus driven $\alpha$ power. It follows that the stimulus-related increase in high-frequency signal entropy mainly accompanies the early phase of the posterior $\alpha$ power desynchronization.

\section{Discussion}

The coordinated dynamics of neural activity in the $\alpha$ and $\theta$ frequency ranges are tightly linked to the timing of decisions about stimulus identity in numerical, verbal, and figural CRTs. The observed dissociations in time and topography point to different roles for neural operations in these frequency bands (Figs. 2 and 4).

Frontocentral $\theta$ band activity is characterized by a gradual increase until response execution. By contrast, after an initial stimulus induced peak, posterior $\alpha$ activity is reduced before response execution and rebounds only afterward. The comparison between STIM and NOSTIM trials (Fig. 5) suggests that these neural mechanisms are involved in evidence accumulation. The NOSTIM trials present a condition where no task-relevant sensory information is available. Accordingly, no evidence accumulation is needed. Hence, the activity patterns observed in the $\alpha$ and $\theta$ bands presumably reflect interactions in cortical networks related to the controlled processing of sensory evidence about decision alternatives.

The frontocentral increases $(\theta)$ and posterior decreases $(\alpha)$ in signal power were paralleled by inverse changes in the signal entropy of EEG frequency components $>30 \mathrm{~Hz}$. Overall, the present results suggest that local changes in neural firing patterns (as approximated by high-frequency signal entropy) are controlled by network activity operating in the $\alpha$ and $\theta$ frequency ranges (compare Hanslmayr et al., 2012). The topographical and temporal similarity across the three task domains underscores the generality of the observed dynamics between decision-relevant mechanisms operating at low and high frequencies.

\section{Frontocentral $\theta$ activity as a possible neural accumulator}

In the present study, the process of decision formation was accompanied by an increase of neural activity in the $\theta$ frequency range over frontocentral regions (see also van Vugt et al., 2012; Guitart-Masip et al., 2013). Neural activity in the $\theta$ frequency range has been suggested to coordinate and integrate information from various sources (e.g., Sauseng et al., 2010; Colgin, 2011; Lisman and Jensen, 2013). One recent study (van Vugt et al., 2012) directly identified activity in the $\theta$ range as an index of evidence accumulation. In addition, using a multivariate GLM framework, van Vugt et al. (2012) observed that $\alpha$ regressors were related to individual differences in drift rates (i.e., the diffusion model parameter that represents efficiency of evidence accumulation) (see Ratcliff, 1978). These findings were interpreted as reflecting a "bleeding in" of $\theta$ activity into the $\alpha$ frequency range resulting from wavelet filtering (van Vugt et al., 2012). In the present report, we demonstrate that the dynamics of neural os- 
cillations in the $\alpha$ and $\theta$ frequency range can indeed be dissociated based on their temporal and spatial profile.

The existence of neural activity patterns in the $\theta$ range is well documented for the hippocampal formation (e.g., Green and Arduini, 1954; Vanderwolf, 1969; Bland, 1986). Nevertheless, the exact neural sources for frontocentral EEG $\theta$ activity remain unclear. One likely mechanism entails the possibility that corticohippocampal feedback loops induce $\theta$ oscillations measurable at the scalp level (Miller, 1991). Given the associative binding capabilities of medio-temporal lobe (MTL) regions in conjunction with the adaptive control functions of PFC (Miller and Cohen, 2001), the interplay between MTL and PFC/ACC regions may allow for the implementation of a general accumulator (see Bland and Oddie, 2001). In line with these suggestions, previous results report sources in ACC and MTL areas, the latter being strongly synchronized with several prefrontal regions (Guitart-Masip et al., 2013). The coordinated processing of information generated in sensory regions may then be synchronized by temporally structuring neural activity in the $\theta$ frequency range (e.g., Hyman et al., 2005; Siapas et al., 2005; Benchenane et al., 2010; Fujisawa and Buzsáki, 2011).

In summary, in line with previous results, the present findings suggest that increases in frontocentral $\theta$ activity during response formation reflect controlled processing states in an interactive PFC-ACC-MTL network in the service of adaptive behavioral responses.

\section{Posterior $\alpha$ activity in the service of controlled sensory processing}

Most studies demonstrating fluctuations in cortical excitability by sensory input focused on the role of $\alpha$ synchronization as a marker for the timing of inhibition (Thut et al., 2006; Hanslmayr et al., 2007; Dijk et al., 2008; Haegens et al., 2011b, c). The modulations of posterior $\alpha$ power observed in the present study are well in line with the proposition that fluctuations in neural $\alpha$ activity represent a general mechanism for the timing of neural inhibition (Klimesch et al., 2007), and the gating of information flow in the brain (Jensen and Mazaheri, 2010).

In particular, the single-trial fluctuations in signal power offer important insights for the role of activity in the $\alpha$ frequency range during perceptual decision making (Fig. 4). An initial peak in $\alpha$ power is found immediately after stimulus onset, but this peak is unrelated to the duration of the decision process as indexed by RT. In contrast, the following relative decrease in $\alpha$ power covaries with RT and is, in turn, followed immediately by a strong $\alpha$ resynchronization. This sequence of events is in good agreement with the notion that sensory information is actively processed during the desynchronized $\alpha$ state (Spaak et al., 2012) and inhibited once a decision has been made (e.g., Romei et al., 2008; Haegens et al., 2011c).

In addition, the initial decrease in $\alpha$ power was accompanied by higher signal entropy. The present study provides first evidence from noninvasive EEG recordings to support the assumption that relative decreases in $\alpha$ activity occur with increases in signal entropy (Hanslmayr et al., 2012) and may thus be used to indicate changes in cortical excitability related to active stimulus processing (Lange et al., 2013). The strongest increase in highfrequency entropy was found during the initial part of $\alpha$ desynchronization. This pattern points to a release from local inhibition (Klimesch et al., 2007; Jensen and Mazaheri, 2010), which is reestablished around the time of response execution. Our interpretation is consistent with the observation that lower $\alpha$ power relates to better memory formation and retrieval (Kli- mesch et al., 1996, 1997; Waldhauser et al., 2012), presumably again for the reason that $\alpha$ desynchronization reflects active information processing (Hanslmayr et al., 2012).

In conclusion, we found that decision-related changes in widespread low-frequency power and local high-frequency entropy are inversely related to each other. We conclude that the cooperation among mechanisms captured by these changes enhances the information density of neural response patterns (e.g., Belitski et al., 2008; Scheeringa et al., 2011) and qualifies as an ensemble of neural codes, or a "neural coding system," in the service of perceptual decision making. Future studies need to explore the generality of this system for other forms of goaldirected behavior.

\section{References}

Axmacher N, Henseler MM, Jensen O, Weinreich I, Elger CE, Fell J (2010) Cross-frequency coupling supports multi-item working memory in the human hippocampus. Proc Natl Acad Sci U S A 107:3228-3233. CrossRef Medline

Bauer M, Oostenveld R, Peeters M, Fries P (2006) Tactile spatial attention enhances gamma band activity in somatosensory cortex and reduces lowfrequency activity in parieto-occipital areas. J Neurosci 26:490-501. CrossRef Medline

Belitski A, Gretton A, Magri C, Murayama Y, Montemurro MA, Logothetis NK, Panzeri S (2008) Low-frequency local field potentials and spikes in primary visual cortex convey independent visual information. J Neurosci 28:5696-5709. CrossRef Medline

Bell AJ, Sejnowski TJ (1995) An information-maximization approach to blind separation and blind deconvolution. Neural Comput 7:1129-1159. CrossRef Medline

Benchenane K, Peyrache A, Khamassi M, Tierney PL, Gioanni Y, Battaglia FP, Wiener SI (2010) Coherent $\theta$ oscillations and reorganization of spike timing in the hippocampal-prefrontal network upon learning. Neuron 66:921-936. CrossRef Medline

Bezerianos A, Tong S, Thakor N (2003) Time-dependent entropy estimation of EEG rhythm changes following brain ischemia. Ann Biomed Eng 31:221-232. CrossRef Medline

Bishop CM (2006) Pattern recognition and machine learning. In: Information science and statistics. New York: Springer.

Bland BH (1986) The physiology and pharmacology of hippocampal formation $\theta$ rhythms. Prog Neurobiol 26:1-54. CrossRef Medline

Bland BH, Oddie SD (2001) $\theta$ band oscillation and synchrony in the hippocampal formation and associated structures: the case for its role in sensorimotor integration. Behav Brain Res 127:119-136. CrossRef Medline

Busch NA, Dubois J, VanRullen R (2009) The phase of ongoing EEG oscillations predicts visual perception. J Neurosci 29:7869-7876. CrossRef Medline

Buzsáki G (2006) Rhythms of the brain. Oxford: Oxford UP.

Buzsáki G, Anastassiou CA, Koch C (2012) The origin of extracellular fields and currents: EEG, ECoG, LFP and spikes. Nat Rev Neurosci 13:407-420. CrossRef Medline

Capotosto P, Babiloni C, Romani GL, Corbetta M (2009) Frontoparietal cortex controls spatial attention through modulation of anticipatory $a$ rhythms. J Neurosci 29:5863-5872. CrossRef Medline

Chalk M, Herrero JL, Gieselmann MA, Delicato LS, Gotthardt S, Thiele A (2010) Attention reduces stimulus-driven gamma frequency oscillations and spike field coherence in V1. Neuron 66:114-125. CrossRef Medline

Cohen MX, Cavanagh JF (2011) Single trial regression elucidates the role of prefrontal $\theta$ oscillations in response conflict. Front Psychol 2:30. CrossRef Medline

Colgin LL (2011) Oscillations and hippocampal-prefrontal synchrony. Curr Opin Neurobiol 21:467-474. CrossRef Medline

Delorme A, Makeig S (2004) EEGLAB: an open source toolbox for analysis of single trial EEG dynamics including independent component analysis. J Neurosci Methods 134:9-21. CrossRef Medline

Donner TH, Siegel M, Oostenveld R, Fries P, Bauer M, Engel AK (2007) Population activity in the human dorsal pathway predicts the accuracy of visual motion detection. J Neurophysiol 98:345-359. CrossRef Medline

Donner TH, Siegel M, Fries P, Engel AK (2009) Buildup of choice- 
predictive activity in human motor cortex during perceptual decision making. Curr Biol 19:1581-1585. CrossRef Medline

Fries P (2005) A mechanism for cognitive dynamics: neuronal communication through neuronal coherence. Trends Cogn Sci 9:474-480. CrossRef Medline

Fujisawa S, Buzsáki G (2011) A $4 \mathrm{~Hz}$ oscillation adaptively synchronizes prefrontal, VTA, and hippocampal activities. Neuron 72:153-165. CrossRef Medline

Grandy TH, Werkle-Bergner M, Chicherio C, Lövdén M, Schmiedek F, Lindenberger $U$ (2013a) Individual $\alpha$ peak frequency is related to latent factors of general cognitive abilities. Neuroimage 79C:10-18. CrossRef Medline

Grandy TH, Werkle-Bergner M, Chicherio C, Schmiedek F, Lövdén M, Lindenberger U (2013b) Peak individual $\alpha$ frequency qualifies as a stable neurophysiological trait marker in healthy younger and older adults. Psychophysiology 50:570-582. CrossRef Medline

Gray CM, Singer W (1989) Stimulus-specific neuronal oscillations in orientation columns of cat visual cortex. Proc Natl Acad Sci U S A 86:16981702. CrossRef Medline

Green JD, Arduini AA (1954) Hippocampal electrical activity in arousal. J Neurophysiol 17:533-557. Medline

Groppe DM, Urbach TP, Kutas M (2011) Mass univariate analysis of eventrelated brain potentials/fields: II. Simulation studies. Psychophysiology 48:1726-1737. CrossRef Medline

Gross J, Ploner M (2009) Perceptual decisions: from sensory signals to behavior. Curr Biol 19:R847-R849. CrossRef Medline

Guitart-Masip M, Barnes GR, Horner A, Bauer M, Dolan RJ, Duzel E (2013) Synchronization of medial temporal lobe and prefrontal rhythms in human decision making. J Neurosci 33:442-451. CrossRef Medline

Haegens S, Händel BF, Jensen O (2011a) Top-down controlled $\alpha$ band activity in somatosensory areas determines behavioral performance in a discrimination task. J Neurosci 31:5197-5204. CrossRef Medline

Haegens S, Luther L, Jensen O (2011b) Somatosensory anticipatory $\alpha$ activity increases to suppress distracting input. J Cogn Neurosci 24:677-685. CrossRef Medline

Haegens S, Nácher V, Luna R, Romo R, Jensen O (2011c) $\alpha$-Oscillations in the monkey sensorimotor network influence discrimination performance by rhythmical inhibition of neuronal spiking. Proc Natl Acad Sci U S A 108:19377-19382. CrossRef Medline

Hanslmayr S, Aslan A, Staudigl T, Klimesch W, Herrmann CS, Bäuml KH (2007) Prestimulus oscillations predict visual perception performance between and within subjects. Neuroimage 37:1465-1473. CrossRef Medline

Hanslmayr S, Staudigl T, Fellner MC (2012) Oscillatory power decreases and long-term memory: the information via desynchronization hypothesis. Front Hum Neurosci 6:74. CrossRef Medline

He BJ, Zempel JM, Snyder AZ, Raichle ME (2010) The temporal structures and functional significance of scale-free brain activity. Neuron 66:353369. CrossRef Medline

Hebart MN, Donner TH, Haynes JD (2012) Human visual and parietal cortex encode visual choices independent of motor plans. Neuroimage 63: 1393-1403. CrossRef Medline

Heekeren HR, Marrett S, Bandettini PA, Ungerleider LG (2004) A general mechanism for perceptual decision-making in the human brain. Nature 431:859-862. CrossRef Medline

Heekeren HR, Marrett S, Ungerleider LG (2008) The neural systems that mediate human perceptual decision making. Nat Rev Neurosci 9:467479. CrossRef Medline

Hyman JM, Zilli EA, Paley AM, Hasselmo ME (2005) Medial prefrontal cortex cells show dynamic modulation with the hippocampal $\theta$ rhythm dependent on behavior. Hippocampus 15:739-749. CrossRef Medline

Jensen O, Mazaheri A (2010) Shaping functional architecture by oscillatory $\alpha$ activity: gating by inhibition. Front Hum Neurosci 4:186. CrossRef Medline

Kayser J (2009) Current source density (CSD) interpolation using spherical splines-CSD Toolbox (Version 1.1). http://psychophysiology.cpmc. columbia.edu/Software/CSDtoolbox. New York State Psychiatric Institute: Division of Cognitive Neuroscience.

Kayser J, Tenke CE (2006) Principal components analysis of Laplacian waveforms as a generic method for identifying ERP generator patterns: I. Evaluation with auditory oddball tasks. Clin Neurophysiol 117:348-368. CrossRef Medline
Kiebel SJ, Tallon-Baudry C, Friston KJ (2005) Parametric analysis of oscillatory activity as measured with EEG/MEG. Hum Brain Mapp 26:170177. CrossRef Medline

Klimesch W, Schimke H, Doppelmayr M, Ripper B, Schwaiger J, Pfurtscheller G (1996) Event-related desynchronization (ERD) and the Dm effect: does $\alpha$ desynchronization during encoding predict later recall performance? Int J Psychophysiol 24:47-60. CrossRef Medline

Klimesch W, Doppelmayr M, Schimke H, Ripper B (1997) $\theta$ synchronization and $\alpha$ desynchronization in a memory task. Psychophysiology 34: 169-176. CrossRef Medline

Klimesch W, Sauseng P, Hanslmayr S (2007) EEG $\alpha$ oscillations: the inhibition-timing hypothesis. Brain Res Rev 53:63-88. CrossRef Medline

Lange J, Oostenveld R, Fries P (2013) Reduced occipital $\alpha$ power indexes enhanced excitability rather than improved visual perception. J Neurosci 33:3212-3220. CrossRef Medline

Le Van Quyen M, Foucher J, Lachaux J, Rodriguez E, Lutz A, Martinerie J, Varela FJ (2001) Comparison of Hilbert transform and wavelet methods for the analysis of neuronal synchrony. J Neurosci Methods 111:83-98. CrossRef Medline

Lee D (2013) Decision making: from neuroscience to psychiatry. Neuron 78:233-248. CrossRef Medline

Lisman JE, Jensen O (2013) The $\theta$-gamma neural code. Neuron 77:10021016. CrossRef Medline

Makeig S, Westerfield M, Jung TP, Enghoff S, Townsend J, Courchesne E, Sejnowski TJ (2002) Dynamic brain sources of visual evoked responses. Science 295:690-694. CrossRef Medline

Makeig S, Debener S, Onton J, Delorme A (2004) Mining event-related brain dynamics. Trends Cogn Sci 8:204-210. CrossRef Medline

Maris E, Oostenveld R (2007) Nonparametric statistical testing of EEG-and MEG-data. J Neurosci Methods 164:177-190. CrossRef Medline

Mathewson KE, Gratton G, Fabiani M, Beck DM, Ro T (2009) To see or not to see: prestimulus $\alpha$ phase predicts visual awareness. J Neurosci 29:27252732. CrossRef Medline

Miller EK, Cohen JD (2001) An integrative theory of prefrontal cortex function. Annu Rev Neurosci 24:167-202. CrossRef Medline

Miller R (1991) Cortico-hippocampal interplay and the representation of contexts in the brain. Berlin: Springer.

Montemurro MA, Rasch MJ, Murayama Y, Logothetis NK, Panzeri S (2008) Phase-of-firing coding of natural visual stimuli in primary visual cortex. Curr Biol 18:375-380. CrossRef Medline

Oostenveld R, Praamstra P (2001) The five percent electrode system for high-resolution EEG and ERP measurements. Clin Neurophysiol 112: 713-719. CrossRef Medline

Oostenveld R, Fries P, Maris E, Schoffelen JM (2011) FieldTrip: open source software for advanced analysis of MEG, EEG, and invasive electrophysiological data. Comput Intell Neurosci 2011:156869. CrossRef Medline

Panzeri S, Brunel N, Logothetis NK, Kayser C (2010) Sensory neural codes using multiplexed temporal scales. Trends Neurosci 33:111-120. CrossRef Medline

Perrin F, Pernier J, Bertrand O, Echallier JF (1989) Spherical splines for scalp potential and current density mapping. Electroencephalogr Clin Neurophysiol 72:184-187. CrossRef Medline

Pfurtscheller G, Aranibar A (1977) Event-related cortical desynchronization detected by power measurements of scalp EEG. Electroencephalogr Clin Neurophysiol 42:817-826. CrossRef Medline

Pfurtscheller G, Lopes da Silva FH (1999) Event-related EEG/MEG synchronization and desynchronization: basic principles. Clin Neurophysiol 110:1842-1857. CrossRef Medline

Philiastides MG, Sajda P (2006) Temporal characterization of the neural correlates of perceptual decision making in the human brain. Cereb Cortex 16:509-518. CrossRef Medline

Philiastides MG, Sajda P (2007) EEG-informed fMRI reveals spatiotemporal characteristics of perceptual decision making. J Neurosci 27:1308213091. CrossRef Medline

Philiastides MG, Ratcliff R, Sajda P (2006) Neural representation of task difficulty and decision making during perceptual categorization: a timing diagram. J Neurosci 26:8965-8975. CrossRef Medline

Quian Quiroga R, Panzeri S (2009) Extracting information from neuronal populations: information theory and decoding approaches. Nat Rev Neurosci 10:173-185. CrossRef Medline

Ratcliff R (1978) A theory of memory retrieval. Psychol Rev 85:59-108. CrossRef 
Rolls ET, Franco L, Aggelopoulos NC, Reece S (2003) An information theoretic approach to the contributions of the firing rates and the correlations between the firing of neurons. J Neurophysiol 89:2810-2822. CrossRef Medline

Romei V, Brodbeck V, Michel C, Amedi A, Pascual-Leone A, Thut G (2008) Spontaneous fluctuations in posterior $\alpha$ band EEG activity reflect variability in excitability of human visual areas. Cereb Cortex 18:2010-2018. CrossRef Medline

Romei V, Gross J, Thut G (2010) On the role of prestimulus $\alpha$ rhythms over occipito-parietal areas in visual input regulation: correlation or causation? J Neurosci 30:8692-8697. CrossRef Medline

Rousselet GA, Pernet CR (2012) Improving standards in brain-behavior correlation analyses. Front Hum Neurosci 6:119. CrossRef Medline

Rousselet GA, Gaspar CM, Wieczorek KP, Pernet CR (2011) Modeling single trial ERP reveals modulation of bottom-up face visual processing by top-down task constraints (in some subjects). Front Psychol 2:137. CrossRef Medline

Sauseng P, Klimesch W, Heise KF, Gruber WR, Holz E, Karim AA, Glennon M, Gerloff C, Birbaumer N, Hummel FC (2009) Brain oscillatory substrates of visual short-term memory capacity. Curr Biol 19:1846-1852. CrossRef Medline

Sauseng P, Griesmayr B, Freunberger R, Klimesch W (2010) Control mechanisms in working memory: a possible function of EEG $\theta$ oscillations. Neurosci Biobehav Rev 34:1015-1022. CrossRef Medline

Scheeringa R, Fries P, Petersson KM, Oostenveld R, Grothe I, Norris DG, Hagoort P, Bastiaansen MC (2011) Neuronal dynamics underlying high- and low-frequency EEG oscillations contribute independently to the human BOLD signal. Neuron 69:572-583. CrossRef Medline

Schmiedek F, Lövdén M, Lindenberger U (2010) Hundred days of cognitive training enhance broad cognitive abilities in adulthood: findings from the COGITO study. Front Aging Neurosci 2:27. CrossRef Medline

Schneidman E, Puchalla JL, Segev R, Harris RA, Bialek W, Berry MJ 2nd (2011) Synergy from silence in a combinatorial neural code. J Neurosci 31:15732-15741. CrossRef Medline

Schroeder CE, Lakatos P (2009) Low-frequency neuronal oscillations as instruments of sensory selection. Trends Neurosci 32:9-18. CrossRef Medline

Shadlen MN, Newsome WT (2001) Neural basis of a perceptual decision in the parietal cortex (area LIP) of the rhesus monkey. J Neurophysiol 86: 1916-1936. Medline
Siapas AG, Lubenov EV, Wilson MA (2005) Prefrontal phase locking to hippocampal $\theta$ oscillations. Neuron 46:141-151. CrossRef Medline

Spaak E, Bonnefond M, Maier A, Leopold DA, Jensen O (2012) Layerspecific entrainment of gamma band neural activity by the $\alpha$ rhythm in monkey visual cortex. Curr Biol 22:2313-2318. CrossRef Medline

Thut G, Nietzel A, Brandt SA, Pascual-Leone A (2006) $\alpha$ band electroencephalographic activity over occipital cortex indexes visuospatial attention bias and predicts visual target detection. J Neurosci 26:9494-9502. CrossRef Medline

Vanderwolf CH (1969) Hippocampal electrical activity and voluntary movement in the rat. Electroencephalogr Clin Neurophysiol 26:407-418. CrossRef Medline

van Dijk H, Schoffelen JM, Oostenveld R, Jensen O (2008) Prestimulus oscillatory activity in the $\alpha$ band predicts visual discrimination ability. J Neurosci 28:1816-1823. CrossRef Medline

van Dijk H, van der Werf J, Mazaheri A, Medendorp WP, Jensen O (2010) Modulations in oscillatory activity with amplitude asymmetry can produce cognitively relevant event-related responses. Proc Natl Acad Sci U S A 107:900-905. CrossRef Medline

van Vugt MK, Simen P, Nystrom LE, Holmes P, Cohen JD (2012) EEG oscillations reveal neural correlates of evidence accumulation. Front Neurosci 6:106. CrossRef Medline

Von der Malsburg C (1981) The correlation theory of brain function. http://cogprints.org/1380 Accessed March 25, 2013.

von Stein A, Sarnthein J (2000) Different frequencies for different scales of cortical integration: from local gamma to long range $\alpha / \theta$ synchronization. Int J Psychophysiol 38:301-313. CrossRef Medline

Waldhauser GT, Johansson M, Hanslmayr S (2012) $\alpha / \beta$ Oscillations indicate inhibition of interfering visual memories. J Neurosci 32:1953-1961. CrossRef Medline

Wang XJ (2010) Neurophysiological and computational principles of cortical rhythms in cognition. Physiol Rev 90:1195-1268. CrossRef Medline

Werkle-Bergner M, Freunberger R, Sander MC, Lindenberger U, Klimesch W (2012) Inter-individual performance differences in younger and older adults differentially relate to amplitude modulations and phase stability of oscillations controlling working memory contents. Neuroimage 60:7182. CrossRef Medline

Whittingstall K, Logothetis NK (2009) Frequency band coupling in surface EEG reflects spiking activity in monkey visual cortex. Neuron 64:281-289. CrossRef Medline 